\title{
Teaching Introductory Quantitative Research Methods to Doctoral Students in Educational Leadership: Using Real Data to Improve Statistical Literacy
}

\author{
Serena J. Salloum ${ }^{1}$, Tamara V. Young ${ }^{2} \&$ Rebecca D. Brown ${ }^{1}$ \\ ${ }^{1}$ Department of Educational Leadership, Ball State University, Muncie, Indiana, USA \\ ${ }^{2}$ College of Education, North Carolina State University, Raleigh, North Carolina, USA \\ Correspondence: Serena Salloum, Department of Educational Leadership, Ball State University, 915 Teachers \\ College, Muncie, IN 47306-0625, USA. Tel: 1-765-285-8413.
}

Received: August 2, 2016

doi:10.5430/irhe.v1n2p203
Accepted: August 25, 2016

Online Published: September 5, 2016

URL: http://dx.doi.org/10.5430/irhe.v1n2p203

\begin{abstract}
The purpose of this study is to provide a deeper understanding of the quantitative research method experiences of educational leadership doctoral students and explore instructors' perspectives on teaching the course through the specific pedagogical approach of using real secondary data. Survey data confirms students favorably support the use of real data in statistics courses, despite challenges to learning statistical software and time constraints that inhibit full engagement in the analyses. Qualitative data illustrates the affordances and constraints instructors face in teaching applied quantitative methods to educational leadership doctoral students.
\end{abstract}

Keywords: educational leadership, quantitative research, doctoral students, real data, instructional methods

\section{Introduction}

Because of a confluence of changes - notably, advances in technology that facilitate data collection and analysis, a data rich culture, calls for data-driven decision making, and a focus on student outcomes-becoming statistically literate is more important for educational leaders now than previous decades. Quite simply, as Steen (2001) pointed out: "The world of the twenty-first century is a world awash in numbers" and quantitative analysis has become "an almost essential skill" (Sobal, 1982). Indeed, the role statistical analysis can play in the world of educational leaders is virtually endless. For example, educational leaders may use statistics to:

- Understand what generalizations can be made from an evaluation of a program or policy;

- Disaggregate student achievement data by race/ethnicity, gender, socioeconomic, disability, or English learner status;

- Determine if a specific initiative is effective, and if so, with which students and under what circumstances;

- Highlight what characteristics or behaviors of teachers are related to teacher effectiveness in their school district or state;

- Identify patterns of principal assignment-e.g., determining to what extent male principals in the school district are more likely to be assigned to low performing schools than their female counterparts; and

- Understand what student behaviors predict the likelihood that a student will drop out of school.

Though educational leaders need to become statistically literate to thrive in their data-drenched environments, knowledge about how to best prepare future educational leaders to meet the data demands of our numbers-obsessed contemporary society remains woefully underdeveloped.

The responsibility for preparing students to be statistically literate is often appointed to the instructor of the introductory and intermediate statistics courses, which are required components of the doctoral curriculum for most educational leadership programs. The ultimate goal of these courses is to have students become statistically literate in order to become critical consumers of educational research, skillful analysts of quantitative data gathered in educational settings, and in some instances, prominent scholars who use statistical methods to carryout research that informs educational policy and practice. Anecdotally (insights gleaned from the authors' experiences teaching 
quantitative research courses), doctoral students in educational leadership programs have the same attitudes and face the same challenges of their peers in other disciplines encountering the same content, such as, finding the course difficult and unpleasant (Smith \& Martinez-Moyano, 2012; Garfield, Hogg, Schau, \& Whittinghill, 2002) and having difficulty linking the abstract nature of research methods to real life situations and dissertation requirements (Benson \& Blackman, 2003; Thompson, 1994).

Though the research on teaching and learning statistics has grown dramatically, there remains many unanswered questions about the nature and development of student's statistical reasoning (Garfield \& Ben-Zvi, 2007; Zieffler, Garfield, Alt, Dupuis, Holleque, \& Chang, 2008). Indeed, statistics education is still viewed as a new and emerging discipline (Garfield \& Ben-Zvi, 2007). The purpose of this paper is to better understand educational leadership doctoral students' experiences with quantitative research methods and their instructors' perspectives on teaching the course. In particular, we focus on a specific pedagogical approach used to improve student-learning outcomes in doctoral-level statistics courses for educational leaders, the use of real data. Studying a specific instructional method is a common practice in the research on statistics education (Zieffler, et al, 2008). For example, Magel (1998) investigated the use of cooperative learning in teaching statistics and found that the use of cooperative learning in a large lecture class improved students' test scores. Specifically, we seek to gain an insight from instructors and students about the use of one type of real data, secondary data, in their introductory research methods class. The research questions guiding this study are:

RQ1: Why have teachers opted to use real data, specifically secondary data, in their introductory quantitative research methods course?

RQ2: How are teachers incorporating secondary data in their introductory quantitative data research methods course?

RQ3: What are teachers' perceptions of the pedagogical advantages and disadvantages using secondary data in their quantitative research methods course?

RQ4: What are students' perceptions of the usefulness of secondary data in learning statistics in their quantitative research methods course?

RQ5: What are students' perceptions of the advantages and disadvantages of using secondary data in their quantitative research methods course?

We are focusing on the use of real data because data are at the heart of statistics (Garfield \& Everson, 2009). If statistics is ultimately about understanding data, students should have experience with analyzing real data (Hall \& Rowell, 2008). Furthermore, using real data is one of six American Statistical Association recommended guidelines for teaching introductory college courses (GAISE, 2005). The aim of this study is to expand understanding of teaching and learning of statistics for doctoral students in educational leadership programs with the goals of: a) reducing the difficulty and unpleasantness students experience when learning this content, and b) increasing learning so that the students can become more effective at navigating the data-saturated landscape in which they operate and carrying out critical quantitative investigations.

\section{Theoretical Background}

\subsection{Statistics Education}

In 2005 the American Statistical Association approved the Guidelines for Assessment and Instruction in Statistics Education (GAISE) for teaching introductory, college statistics. With the intent of making these courses more modern, engaging, and authentic, GAISE specified six recommendations: a) emphasize statistical literacy and develop statistical thinking; b) use real data; c) stress conceptual understanding rather than mere knowledge of procedures; d) foster active learning in the classroom; e) use technology for developing conceptual understanding and analyzing data; and f) integrate assessments that are aligned with course goals to improve as well as evaluate student learning. Although there has been a flurry of activity surrounding these recommendations, including presentations, workshops, publications, and the development of National Science Foundation Grant-funded survey that assesses instructors' practices and beliefs about the teaching and learning of statistics (Zieffler et al, 2008), little research has been conducted on the implementation and effectiveness of these instructional recommendations, in general, and for doctoral students in educational leadership programs in particular. In this study, we endeavor to provide empirical evidence about one specific recommendation, using real data, with the intent of advancing our knowledge base about how best to prepare statistically literate educational leaders who are critical consumers of educational research and savvy data analysts for school districts, state educational agencies, college and universities, and research or policy organizations. 


\subsection{Using Real Data: A Case for Secondary Data in Introductory Courses}

According to GAISE (2005), in addition to enlivening the class, there are several advantages to using real data in introductory statistics courses.

It is important to use real data in teaching statistics to be authentic, to consider issues related to how and why the data were produced or collected, and to relate the analysis to the problem context. Using real data sets of interest to students is also a good way to engage them in thinking about the data and relevant statistical concepts. (p. 16)

Although there are different types of real data — class generated, archival, and simulated - that can be used to accomplish these goals, this paper focuses on the use of archival data, also known as secondary data.

As Sobal (1982) pointed out: "inquiry and methodology are processes, and are best learned by actually conducting research. Secondary data analysis, the reanalysis of machine-readable data, is one of the best supplements to traditional teaching methods, especially for teaching research methodology and statistics" (p. 480). Secondary data analysis is particularly useful to learning statistics because "statistics and analysis are meaningful to social scientists as tools for understanding data rather than ends in themselves. Thus data become an important part of methodological training, and the reanalysis of previously collected data is one of the best ways of teaching research methodology" (p. 480). Secondary data also gives students "experience with real-world statistics and can be complex and rich in nature" (Hall \& Rowell, 2008, para. 6). Furthermore, secondary data can be easy to access in the field of education because there are a plethora of large and sophisticated state and national secondary datasets that are designed to answer a wide range of education questions across different units of analysis (e.g., National Assessment of Educational Progress, Early Childhood Longitudinal Study, School and Staffing Survey, North Carolina Working Conditions Survey).

Another key advantage to using real data, specifically secondary data, in teaching quantitative research methods courses is that secondary data can be relevant (Sobal, 1981; Garfield, delMas, \& Zieffler, 2010).

Students are not strongly motivated to work with trivial issues or low quality information, and using high quality secondary data inspires students to take learning seriously rather than seeing it as a series of irrelevant pedagogical tasks or 'busywork.' Much of the available secondary data are current and timely (Cutler, 1978). This gives impetus to the creative interpretation of data by students, who frequently become 'ego-involved' (Davis, 1978) in the reality testing of their own social hypotheses. This method of inductive teaching forces students to actively examine society rather than passively accepting what they are told (Sobal, 1981, p. 150).

This engagement with data can lead to students becoming "more excited about the ability of statistical procedures to allow them to test their hypothesis" (Sobal, 1981, p. 152). Furthermore, as the course proceeds from descriptive to inferential and univariate or multivariate analyses of the same real data set, students begin to see the value of more powerful statistical techniques. Moreover, as Sobal (1981) pointed out, results can also be discussed in the class and triangulated with other sources (e.g., personal experience, primary data, other secondary data, or census information). This aligns with the mathematical practice of Model-Eliciting Activities (MEAS), specifically the reality principle, in which student teams "generate solutions...to authentic, real-world problems" using meaningful and relevant design (Garfield, delMas, \& Zieffler, 2010).

These advantages provide a compelling line of reason to include secondary data in quantitative research methods courses for doctoral students in education. As such, some faculty, who teach students enrolled in educational leadership programs, have begun to incorporate secondary data in their introductory statistics course. However, little is known about how these faculty are using secondary data in their classrooms and students' experiences with the secondary data, as well as what learning outcomes are associated with the use of secondary data. With few faculty in educational leadership programs having undergone training to teach quantitative research methods - there are very few courses that are focused on the preparation of teachers of statistics (Garfield \& Ben-Zvi, 2008) - and consistent evidence that indicates that college level students have difficulty learning, remembering, and using statistics (Garfield \& Ben-Zvi, 2007), there is much to learn about the teaching and learning of statistics in doctoral programs for educational leaders.

In sum, educational leaders need facility with the analysis and interpretation of data to better inform educational practice. To this end, it behooves educational leadership programs to provide such courses that are applicable, as students learn best from first hand experience. One particular recommendation from GAISE is to use "real data" in class. This paper is the beginning of an empirically based conversation about the use of the American Statistical 
Association's recommended pedagogical strategies in quantitative research courses for doctoral students in educational leadership programs.

\section{Method}

\subsection{Sample and Data Collection}

The sample was comprised of educational leadership doctoral students enrolled in introductory quantitative courses at two universities from 2011-2012. The researchers obtained the email addresses of educational leadership doctoral students from course instructors' records and then emailed a letter to students explaining the purpose of the study. The email also included a link to a Qualtrics survey that was used to collect participants' anonymous responses. The response rates were $70.83 \%$ for University A, $85.7 \%$ for University B, and $74.19 \%$ overall. As shown in Table 1, we asked student respondents 17 items that addressed: demographic information, anxiety about the course, perceived success in the course, perceived usefulness of statistics, usefulness of large data sets, beliefs about whether secondary data facilitate student learning, and perceived usefulness of secondary data. Students selected a Likert scale response for each item (strongly disagree, disagree, neither disagree nor agree, agree, and strongly agree). Students responses to the quantitative data were used to answer research question four. To answer research question five, students were also asked to respond to open-ended questions that asked them to share: (a) how the instructors can make the use of real data in the course more authentic and engaging; (b) what they liked least and most about using real data; and (c) what data sets they would recommend instructors use. Additionally, to answer research questions one, two, and three, we asked the instructors to respond to several open-ended questions:

- Tell me about how you began teaching this course and explain how long you have been teaching it.

- Why have you opted to use real data? What data set? Why this data set?

- What do you believe to be the advantages to teaching and learning using real data? (as it relates to doctoral students in education leadership)

- What do you believe to be the disadvantages to teaching and learning using real data? (as it relates to doctoral students in education leadership)

- What changes will you make in response to lessons learned? What would you incorporate as you move forward? (as it relates to doctoral students in education leadership)

\subsection{Analysis}

To analyze the quantitative data associated with research question four, we first recoded the Likert data (where strongly disagree $=1$, disagree $=2$, neither disagree nor agree $=3$, agree $=4$, and strongly agree $=5$ ) and examined the associations among the items to identify latent factors by performing principal components factor analysis with varimax rotation. Table 1 describes the results of the factor analysis, which confirmed four factors, and presents the Cronbach's coefficient alphas, which assess the internal consistency of each of the factors. We then computed the means and standard deviations for each of the factors and generated Pearson's correlation coefficients among the four factors.

Students' responses to the open-ended questions were coded using inductive analysis, specifically pattern coding to identify emergent themes (Miles \& Huberman, 2013). Since we only had two instructors in the sample and their answers were relatively short, we included their complete responses to items and incorporated specific examples that exhibited some of their comments.

\section{Results}

We organize the findings according to the five research questions guiding this study. Overall, the findings show that both teachers and students believe that using secondary data in an introductory research methods course facilitates learning but there are some challenges to using secondary data that need to be overcome.

RQ1: Why have teachers opted to use real data, specifically secondary data, in their introductory quantitative research methods course?

\section{Instructor A: Imitation, Context, Best Practice}

Instructor A described her doctoral training as "paramount" in shaping her approach to the teaching of quantitative methods; she attended a research-intensive institution full-time, and was engaged in research projects in tandem with immersion in coursework. In her words:

In my own experience as a doctoral student, I used real data in all of my quantitative methods courses. As a 
student, I was engaged by having the opportunity to examine real data and when I came to teach this course myself, I thought this approach made sense.

While this decision initially was primarily about imitation, Instructor A spent professional time examining best practice. After teaching the course two times (at different institutions) Instructor A spent substantial time working on revamping the course. As part of this restructuring she sought professional development. She described her experience,

This summer I went to a workshop sponsored by AERA about teaching statistics with large scale datasets - I learned so much! I felt like the approach I have been using [using real data] was verified by that experience, as the focus of the training was productive approaches to using datasets. I left with a better understanding of how to improve my practice in addition to feeling like I was making the best decisions to support my students' learning.

Instructor A went on to describe the opportunity as "key" in convincing her that this approach is not only considered best practice, but more efficient ways to utilize data in teaching the course (which is described below). Instructor A also made it clear that using real data contextualizes the statistical experience for students.

I liken teaching this course with real data to the teaching of grammar through writing as opposed to using worksheets - it contextualizes it. Using real data makes the course more appealing and relevant to educators and facilitates a more authentic experience.

Instructor A extrapolated that using real data allows students to consider questions they might be grappling with in practice, and it allows them to better comprehend the numbers. She felt that using such authentic instruction would make the course meaningful to students and allow them to connect the content to their prior experience and knowledge.

\section{Instructor B: Imitation, Naivety, and Strategy}

Similar to Instructor A, Instructor B shared that she initially used secondary data to teach quantitative research methods because her instructor used secondary data in her graduate program that she began thirteen years ago. Instructor B explained this decision by relating:

My graduate school instructor was a world renown quantitative methods scholar, and I thought that if anyone would know how best to teach statistics, he would. Not to mention, I enjoyed the class and learned a lot. So, I imitated his approach.

Instructor B also said that even though she likely made an uninformed decision, in that she did not examine the literature on statistics education or adult learning theory, she unintentionally made what she considered a "good choice." Instructor B also indicated that she selected secondary data because she did not know how she would generate the "sheer number of items" that she would need for examples and problems for assignments because the textbook she had selected did not have an instructional manual with a question bank.

Additionally, Instructor B thought that there was a significant personal advantage to using a secondary data set, she remarked: "I thought that by using a secondary data set in class, I would become familiar with it and could use it for future publications. I also thought that I would be forced to learn more about the nuances of analyzing large, complex data sets." Instructor B also admitted that when she first began teaching the course, she even used the same secondary data set she used in graduate school because she was not aware of other options. In her reflection, Instructor B shared that she was naïve about teaching statistics and she was essentially assigned to teach the course because she had more background coursework and experience (part of her dissertation included logistic regression analysis) than her peers in her department. Instructor B also stated that while her initial choice was "uninformed," she still uses secondary data in her class because she now believes that it "facilitates learning and increases her proficiency as a researcher." She imagines that faculty currently not using secondary data will move in that direction.

\section{RQ2: How are teachers incorporating secondary data in their introductory quantitative data research methods course?}

\section{Instructor A and Instructor B: Teacher Demonstration and Student Application}

Both instructors highlighted two primary ways they utilized data: through teacher demonstration and student application. Instructor A currently uses the Early Childhood Longitudinal Study (ECLS-K) and is considering adding other datasets as she continually refines and improves the course. In her account of data use, she described modeling statistical analyses "everything from how to run univariate to multivariate analyses" as well as how to demonstrate 
particular concepts. For example, Instructor A explained that she displays concepts such as the central limit theorem through using the dataset as a population.

I use ECLS-K to represent a population to illustrate concepts like the central limit theorem. For example, we run descriptive statistics of population across a few variables to show the "true" values. Then we draw repeated random samples and collect descriptive statistics for each to illustrate the similarity of those descriptives to the population.

Not only did Instructor A utilize data in her instruction, she also had students utilize data in their assignments. Instructor A described the assignments through which students progressed during the semester, all that required analysis and interpretation of a subset of the ECLS-K dataset.

I structure four assignments and a final project for students. Each assignment is focused on a research question and students are required to perform analysis and interpret data to respond to the research question. As the semester continues I provide less scaffolding so students have the freedom to explore research questions that are of interest to them. Students are required to write-up all results as a mini-research paper, so I think about this class just as much as a writing course as a class on statistics.

Instructor B currently uses the High School Longitudinal Study (HSLS 09) but has used other data sets in previous years, specifically NELS and ELS (2002). Similar to Instructor A, she uses the data sets largely in two ways. First, she incorporates analysis of secondary data during the lecture, as part of some of the examples of statistical concepts, and when demonstrating how to use SPSS to compute statistical analysis. For example, in teaching how to compute ANOVA in the spring semester of 2012, Instructor B used the following Powerpoint ${ }^{\circledR}$ slides based on some data from (she believes) HSLS 09 to show students an example of how to analyze a research question of interest to policymakers and practitioners: What is the difference in mathematics achievement for different race/ethnicity groups?

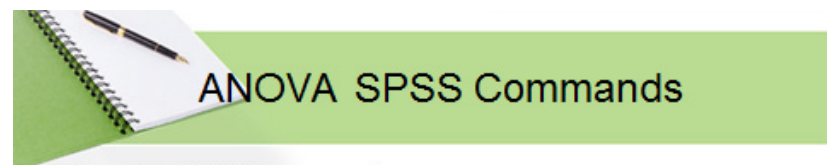

From the SPSS menus choose:

- Analyze

Compare Means

One-Way ANOVA..
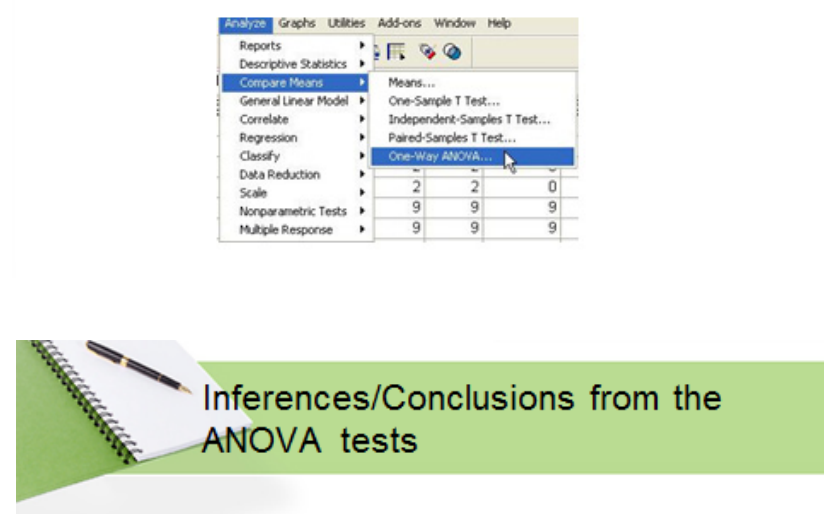

- INFERENCE: The only inference that can be made from ANOVA tests where we have rejected the null hypothesis is that at least one population mean is different from at least one other population mean.

- ${ }^{* \star *} A N O V A$ does not indicate which population means differ from which others. ${ }^{* * *}$
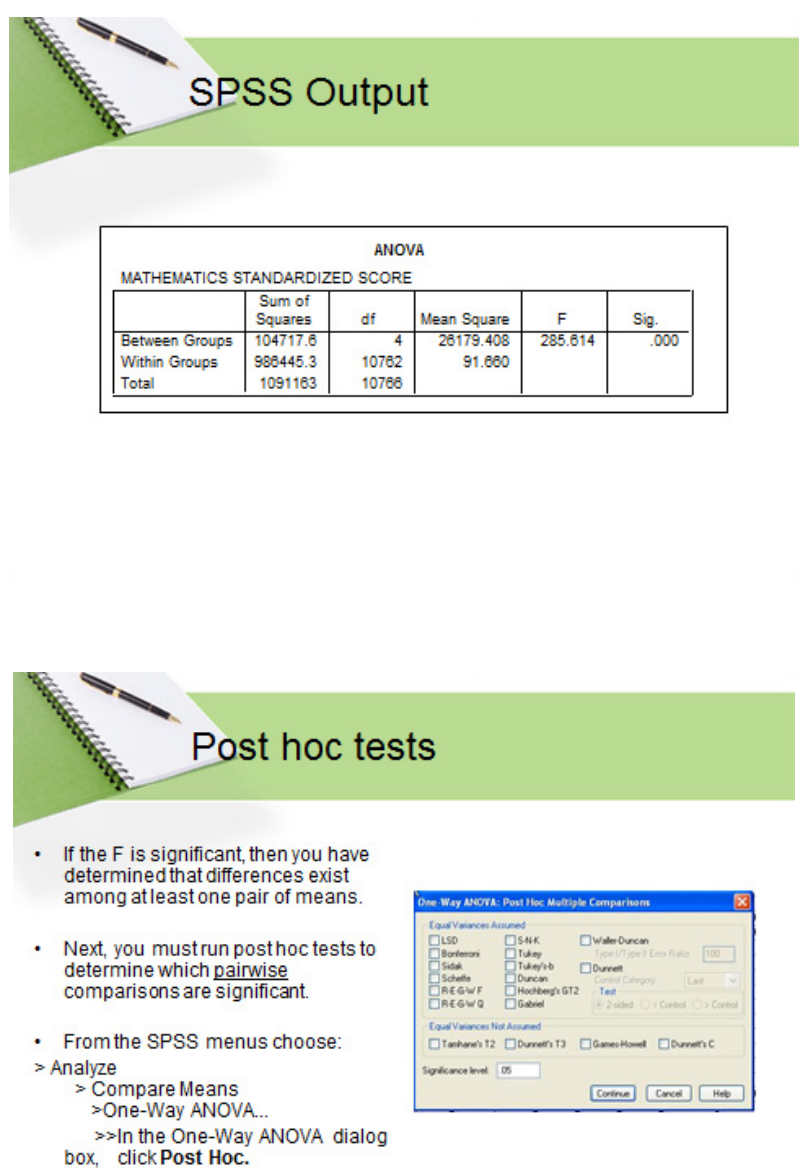


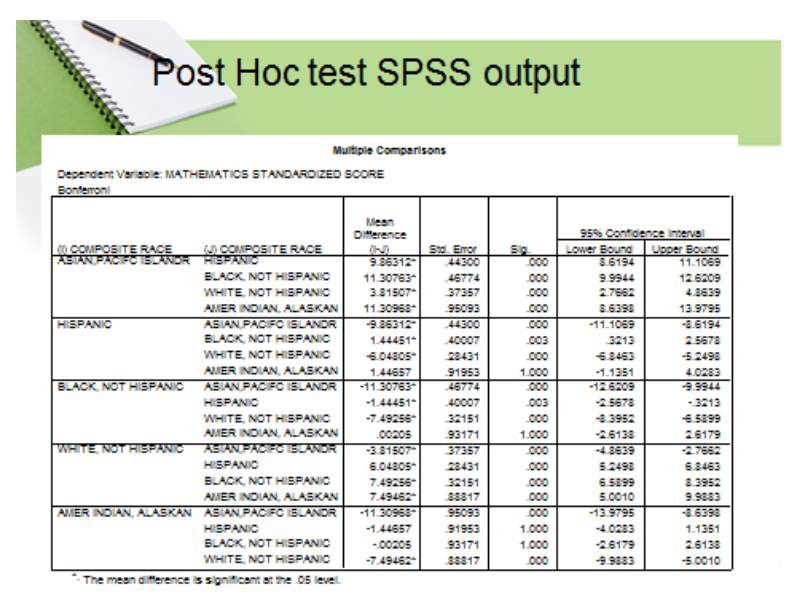

Figure 1. Example of Instructor B's use of SPSS to explain concepts

Though these are only 5 slides of the 20 -slide presentation, in Figure 1 we see evidence of her use of secondary data to show students how to use SPSS and explain a statistical concept.

Second, in Instructor B's class students analyze the data set as they work through their problem sets. In particular, each problem set has three components: a) multiple choice questions that examine students' knowledge about statistical constructs, b) hand computations of mock data examples, and c) statistical analysis of mock data and secondary data. She explained her decision to incorporate the three components:

I think that it's not only important for students to demonstrate an understanding of concepts, but also to thoughtfully apply the concepts. The mock data examples typically have a small sample size. Educational samples are rarely small. I want students to be able to analyze large data sets, and I want students to see data that the hard core quantitative researchers use. I want them to experience the messiness of data analysis.

An example from one of her assignments (Figure 2), Problem Set \#4, shows how students analyze the relationship between variables in HSLS. 
Part A. HSLS 2009

Mulling over contemporary issues using real data is a great way to learn about statistical concepts and procedures. Students will use data from the HSLS to examine various research questions. As stated on the first day of class, this data set is based on a complex sample. As such, there are some additional procedures that should be performed prior to analyses (e.g., missing value analysis, weighting, and discerning if there are school effects due to the hierarchical or clustered nature of the data). However, these advanced procedures are beyond the scope of this class. Therefore, you should be cautious in your interpretation of the findings (i.e., if you want to share the results with peers outside of this class). For all assignments, we will act (and hence interpret) as if this data comes from a random sample of independent observations.

We will focus our attention primary research question:

What student and teacher characteristics are related to students' experiences in their $9^{\text {th }}$ grade math class and their math achievement?

*****We will focus our attention on the same variables we analyzed in PS \#1. Additionally, please use the data that has been recoded to address missing data values. ${ }^{* * * * * *}$

Specifically, we will focus on six variables for Part A. To facilitate navigation of the data set, you may delete all of the other variables if you wish. However, once you do, save as "Problem Set 4." We will use other variables from the original 14 in the near future.

- X1 Student's sex

- $\quad$ S1 C06A 9th grader is enjoying fall 2009 math course very much

- X1 Quintile coding of X1SES composite

- X1 Mathematics quintile score

- X1 Socio-economic status composite

- X1 Mathematics standardized theta score

\section{Statistical Analyses in SPSS}

Run appropriate statistical analyses (two-tailed, alpha level $=.05$ ) for $a$ and $b$ above. Run two analyses for $\mathrm{c}-\mathrm{c} 1$ and $\mathrm{c} 2$ (Pearson's $\mathrm{r}$ and simple linear regression). Include output and syntax from SPSS.

a. X1 Student's sex and S1 C06A 9th grader is enjoying fall 2009 math course very much

b. X1 Quintile coding of X1SES composite and X1 Mathematics quintile score

c. X1 Socio-economic status composite (the one that we recoded) and X1 Mathematics standardized theta score

- Write the null hypothesis (equation and in words) for a, b, c1, and c2.

- Write the alternative hypothesis (equation and in words) for a, b, c1, and c2.

- Run the analysis in SPSS for a, b, c1, and c2. Copy and paste the syntax and the output. Do you reject the null hypothesis? Explain.

- Write up the results as you would for APA for a, b, c1, and c2. See Green and Salkind (they provide examples of write-ups at the end of each unit)

- Now, present the results (for a, b, c1, and c2) in an APA formatted table (see APA $6^{\text {th }}$; it provides specific details on how to create a table for many of the statistical tests that we run--it is not the exact output table provided by SPSS or find examples by googling APA examples).

- What does it all mean (in brief for a, b, $\mathrm{c} 1$, and $\mathrm{c} 2$.)? - explaining it to a person unfamiliar with statistics. Do not use any statistical jargon (avoid significance, reject/accept, hypothesis, probability, statistics). Keep it simple.

Figure 2. Example of Instructor B's use of secondary data in student assignments 
RQ3: What are teachers' perceptions of the pedagogical advantages and disadvantages using secondary data in their quantitative research methods course?

\section{Instructor A: Application and Nuanced Thinking}

Instructor A explained that the primary advantages for using real data sets were for such application and developing critical thinking. She elaborates,

The advantage of using real data is that students can ask questions of the data and actually apply the implications to their particular settings. For example, students in my class were curious how different family configurations related to student achievement [in ECLS-K]; we were able to build models controlling for different variables to ascertain if there was a difference. Such authentic inquiry helps doctoral students nuance their problem solving abilities in their practice and with regard to building their scholarly capacity.

Though Instructor A was asked about the disadvantages in using real data, she continued to focus on the positive reasons for doing so. She mentioned that real data do not always "behave" the way you might hope and continued to explain how this actually was an advantage,

Sometimes you do not get the results you might hope for - but I think these are productive experiences for students. Again, students were considering if number of books in a household were related to incoming literacy scores and were surprised that there wasn't a statistical association. Yet, the lack of relationship between such variables caused more critical reasoning: the mere presence of books was not enough to spur achievement, rather it is how books are used. Such learning opportunities also allow students to understand limits if data and consider issues of measurement.

Instructor A felt that such experiences in considering measurement providing critical thinking skills that were directly applicable to the political context in which her students worked. In her words,

So often in the policy landscape in [state where she teaches], if a number is attached to something, it is accepted as valid and true. Taking a course such as this where students really consider the data, how it is measured, what it means, what the implications of analysis are... it forces educational leaders to be critical consumers of data and how to use it productively as well as how to nuance their thinking about it.

\section{Instructor B: Real, Familiar, and Threaded vs. Timely, Distant, and Complex}

Instructor B acknowledges that she has only anecdotal data, "not even adequate comparisons for a counterfactual," but she firmly believes that secondary data facilitates student learning. She thinks that it improves student engagement and learning because the data is "real" and the variables are "familiar." What she most likes about using secondary data is that it can be the "thread" of the examples and problem sets. She explained this idea of threading with the following example:

On the first problem set we compute measures of centrality (or center) and variability on certain variables, for example, math achievement and race/ethnicity. On another problem set, students will be required to select the appropriate graph or frequency distribution for these same two variables. Then, when we get to ANOVA, students will examine the relationship between these same variables. Students begin to see the connections between the different procedure and they often ask questions that are likely related to a future lesion. In this case, some student might ask: 'How does gender matter here.' That leads to Two-Way ANOVA. And so on. Secondary data is a great way to scaffold.

In order to understand one of the major challenges that Instructor B faces, it is important to understand her context. Explaining her setting, Instructor B wrote:

I teach at a large school whose College of Education is not currently top ranked but striving to be. What this means for me is that my students aren't like me when I was a graduate student. I went to a school where all of the students were full-time and supported by fellowships and grants. That means that school was our life. I had a lot of time to dedicate to learning. I had time to perform complicated statistical analyses. I had time to talk about the concepts with my full-time status peers. Nearly all the students I work with now are part-time. Students in educational leadership have the greatest limitations on their time, they're school principals - need I say anything else about their time.

Instructor $\mathrm{B}$ further explained that this limitation on time made teaching and learning statistics even more challenging than it already is. Instructor B believed that this lack of time meant that students did not have sufficient time to truly engage with the analysis of secondary data. Instructor B surmised that using artificial and small data examples would possibly reduce the time required to complete assignments but also supposed that "so much would 
be lost in terms of authenticity and engagement." Instructor B shared that each time she teaches the course she "evolves" and makes modifications that "better fit the needs of the students without sacrificing quality" and what she terms "the beauty of learning." Another disadvantage of using secondary data relates to the specific data set she uses. Describing the challenge of using a national data set, instructor B disclosed:

With so many advancements in state and district level data collection and students coming to class with some experience analyzing data - at the simplest level of course - I plan on using state level data in the near future. That is, if I can gain access. I believe that students will better connect to the data, learn more, and be able to apply it to their settings if the data is close to them - not too close, I don't want the class to be about criticizing some school or district. I don't want this class to become data-based decision making; that's a masters course. But, I do need to find a balance between close and not too close. I get mesearch [sic], but I want students to be able to see the statistical concepts applied in their setting and beyond. If the data is 'local' then I fear students will not be able to extrapolate to higher levels and different types of questions.

The other two key challenges that Instructor B faces - technology and the nuances of complex samples-are inexplicably tied to secondary data sets so avoiding them is not possible. Instructor B described the technology hurdle by stating, "using secondary data requires using a sophisticated data analysis software like STATA, SPSS, or SAS, and many students find learning to use these programs time consuming, if not confusing." However, according to Instructor B, the resources on these programs - online tutorials with screenshots, you tube videos, textbooks, and the help dialog boxes within the programs-increase in number and quality exponentially every few years. Lastly, the fact that most national data sets are complex samples also can be a nuisance. Instructor B explains to students that the data is clustered (i.e., the observations are not independent) and there are statistical weights (related to sampling procedures) that can be used for analyses, but she feel students are not "ready" to fully understand her explanation and what it means for their current efforts and possible future sophisticated analyses they may perform in other courses or as part of their own research.

RQ4: What are students' perceptions of the usefulness of secondary data in learning statistics in their quantitative research methods course?

As shown in Table 2, respondents, on average, indicated that they agreed to strongly agreed $\left(\mathrm{M}_{1}=4.72, \mathrm{SD}_{1}=.40\right.$; $\left.\mathrm{M}_{2}=4.25, \mathrm{SD}_{2}=.42 ; \mathrm{M}_{\text {total }}=4.60 ; \mathrm{SD}_{\text {total }}=.45\right)$ that real data facilities student learning, as it relates to engaging students thinking about data and relevant statistical concepts, encourages students to consider issues related to how and why data were produced, encourages students to relate analysis to the problem context, and helps students formulate good questions. Table 3 presents the Pearson correlation coefficients among the four factors examined. The results show that students' perceptions of real data facilitating student learning was not related to their perceived usefulness of statistics but was positively associated with whether they believed that they would use a large data set in the future $(\mathrm{r}=.38, \mathrm{p}<.10)$ and their perceived usefulness of large data sets in future professional or academic endeavors $(\mathrm{r}=.42, \mathrm{p}<.05)$.

RQ5: What are students' perceptions of the advantages and disadvantages of using secondary data in their quantitative research methods course?

To answer this question, we relied on students' responses to prompts asking students how we could make the use of real data more engaging and authentic and what did they like the most and least with working with the secondary data sets. Students consistently indicated that they would have preferred to use state or district level data rather than national data, which they believe would have made it "personal," "target the audience," and "make it easier to internalize" statistical concepts. Students suggested different types of state or district level data that they would be interested in using in the course: graduation rates, SAT, ACT, demographic data, state achievement data, NWEA, ACUITY, end of grade or course assessments, and teacher retention data.

Students perceived several advantages to using a secondary data set. First, they believed the data were relevant to their professional careers, helping them view data in their professional setting differently. As one student explained: "It caused me to think about how that data applied to my school." Other students remarked of their change in view of data: "If we were using manufactured data, I probably wouldn't have wondered about that connection [between class and professional life]," and "I can tell you that we use data all the time in our decision making; however, the way I think about it now is light years away from what I did before this course." Second, using real data also facilitated the interpretation of the results. In the words of one doctoral student: "Because the data was [sic] educationally based, I understood what information I was analyzing." Another student commented on how real data made interpretation easier by saying: "I don't like the fantasy world. It made the numbers make sense." 
Students also shared that they believed that one disadvantage associated with analysis of secondary data in an introductory course is learning the software program, in this case SPSS. For example, students remarked that they had "technical issues", "navigation was confusing," and "mechanics of SPSS was a problem." They wanted additional time and technical assistance learning how to use SPSS. Students were also concerned about interpreting the results. The issues with interpretation were due to not understanding how to read output or the nature of the data - not knowing how the data were collected or a slight mismatch between the research question and the data.

\section{Discussion}

\subsection{Key Findings}

Compared to other areas of educational scholarship, including research on educational leaders, the literature on teaching and learning statistics is still relatively new (Garfield \& Ben-Zvi, 2007). However, with the need to collect, analyze, and generalize statistical data is increasingly on the rise, and educational leadership doctoral programs need to learn how to better prepare leaders to thrive in their data-drenched settings. As one of the students in this study remarked: "As educators in schools we look at numbers with a very basic caveman like understanding...But as leaders and thinkers in education we need to make a shift in this direction in our decision making." Although the why of improving quantitative research courses is evident, the how of improvement is woefully underdeveloped. The intent of this study is to provide thoughtful fodder for stimulating empirically based discussions on how to improve the teaching and learning of statistics. This study brings our attention to the crux of statistics, for that matter all research, data. In particular, this study sought insight from both instructors and students about the use of one type of real data, secondary data, in their introductory research methods classes.

The results show that generally instructors and students have a favorable view of using secondary data in introductory methods courses, and they believe that it facilitates learning. In brief, both instructors felt that the advantages of using real data were making statistical concepts more familiar, developing critical thinking, and illustrating to students the "threaded" nature of quantitative inquiry. Instructor A and B had a slightly different opinion on the disadvantages of using real data: Instructor A did not recognize much of a drawback with this approach whereas Instructor B felt that were some limitations. She described the busy lives of her doctoral students as practicing educational administrators; this lack of time made in challenging for students to engage with the content as much as she might like. In addition, there is complexity in the collection of national data, which students may not fully understand. To that end, Instructor B mentioned the idea of utilizing state level data (if she was able to gain access) to improve the contextual nature of using real data with her students.

\subsection{Implications}

Overall, the findings support GAISE's (2005) argument that using real data can improve authenticity and engagement in college level statistics courses. The results also suggest that there are some aspects of using secondary data in quantitative courses that include students from educational leadership doctoral programs instructors must consider. First, the data set should be at a level that interests students (school, district, or state). Because many doctoral students now have some experience reviewing or analyzing data (not the case a decade ago), using data that is familiar to them may increase engagement and improve their ability to apply what they learn to their professional settings. Second, instructors need to dedicate a considerable amount of time to teaching students how to use the statistical software program. Analysis of secondary data cannot be done without sophisticated statistical analysis software programs, and many students have difficulty using these programs. Indeed, learning the technology may be impeding the learning of statistical analyses. Lastly, new instructors of quantitative research methods will likely benefit from a learning community or a workshop on teaching and learning statistics, especially to students in educational leadership programs. Though one instructor sought professional development, both instructors in this study reported simply teaching how they were taught. This approach is effective only when the instructor has a model that used sound pedagogical strategies.

\subsection{Limitations and Directions for Future Research}

This study does not link this specific pedagogical approach, using secondary data, to actual learning outcomes. This drawback is not only a deficit of this study, but also most studies in statistics education (Garfield \& Ben-Zvi, 2007). Designing studies with sophisticated comparisons (i.e., experimental or quasi-experimental design) are costly and not used at the doctoral level. Ironically, it might be rich qualitative data that is necessary to truly explain how using secondary data, or any other instructional approaches in quantitative research courses, enhance student learning. Additionally, the instructional strategy of using secondary data is not used in a vacuum. Other strategies and circumstances are at play as well. Lastly, the findings reflect one type of real data - archival data or secondary 
data - the specific data sets the instructors used, and the ways in which the instructors incorporated secondary data sets in their classrooms. Future studies need to explore the use of other types of real data in the classroom since they are likely to have different advantages and disadvantages. In doing so, we can begin to investigate not only whether incorporating real data improves engagement and authenticity, and ultimately student learning, but also when and with whom each type of data is most effective.

\section{References}

Benson, A., \& Blackman, D. (2003). Can research methods ever be interesting? Active Learning in Higher Education, 4, 39-45. http://dx.doi.org/10.1177/1469787403004001004

Garfield, J., \& Ben-Zvi, D. (2007). How students learn statistics revisited: A current review of research on teaching and learning statistics. International Statistical Review, 75(3), 372-396. http://dx.doi.org/10.1111/j.1751-5823.2007.00029.x

Garfield, J., \& Ben-Zvi, D. (2008). Developing students' statistical reasoning: connecting research and teaching practice. New York: Springer. http://dx.doi.org/http://dx.doi.org/10.1007/978-1-4020-8383-9_13

Garfield, J., \& Everson, M. (2009). Preparing teachers of statistics: A graduate course for future teachers. Journal of Statistics Education, 17(2). Retrieved from www.amstat.org/publications/jse/v17n2/garfield.html

Garfield, J., Aliaga, M., Cobb, G., Cuff, C., Gould, R., Lock, R., \& Witmer, J. (2005). Guidelines for assessment and instruction in statistics education (GAISE): College report. Endorsed by the executive committee of the American Statistical Association.

Garfield, J., delMas, R., \& Zieffler, A. (2010). Developing tertiary-level students' statistical thinking through the use of model-eliciting activities. from https://www.stat.auckland.ac.nz/ iase/publications/icots8/ICOTS8_8B3_GARFIELD.pdf

Garfield, J., Hogg, B., Schau, C., \& Whittinghill, D. (2002). First courses in statistical science: The status of educational reform efforts. Journal of Statistics Education, 10(2). Retrieved from www.amstat.org/publications/jse/v10n2/garfield.html

Hall, M.R., \& Rowell, G.H. (2008). Introductory statistics education and the National Science Foundation. Journal of Statistics Education, 16(2). Retrieved from www.amstat.org/publications/jse/v16n2/rowell1.html

Magel, R. C. (1998). Using cooperative learning in a large introductory statistics class. Journal of Statistics Education, 6(3). Retrieved from http://www.amstat.org/publications/jse/v6n3/magel.html

Miles, M. B., \& Huberman, A. M. (2013). Qualitative data analysis ( $3^{\text {rd }}$ ed.). Thousand Oaks, CA: Sage.

Smith, A., \& Martinez-Moyano, I. J. (2012). Techniques in teaching statistics: Linking research production and research use. Journal of Public Affairs Education, 18(1), 107-136.

Sobal, J. (1981). Teaching with secondary data. Teaching Sociology, 8(2), 149-170. http://dx.doi.org/http://dx.doi.org/10.2307/1316942

Sobal, J. (1982). The role of secondary data analysis in teaching the social sciences. Library Trends, 39(3), 479-488.

Steen, L.A. (2001). Mathematics and democracy: Case for quantitative literacy. The National Council on Education and the Disciplines. Retrieved from http://www.maa.org/q1/mathanddemocracy-ip.htmlhttp://www.maa.org/q1/mathanddemocracy-ip.html

Thompson, B. (1994). Making data analysis realistic: Incorporating research into statistics Modules. Teaching of Psychology, 21, 41-43. http://dx.doi.org/10.1207/s15328023top2101_9

Zieffler, A., Garfield, J., Alt, S., Dupuis, D. Holleque, K., \& Chang, B. (2008). What does research suggest about the teaching and learning of introductory statistics at the college Level? A review of the literature. Journal of Statistics Education, 16(2). Retrieved from www.amstat.org/publications/jse/v16n2/zieffler.html 